\title{
Ebola and the WHO: a journey from toothless tiger to global dragon?
}

\author{
Following the West African Ebola outbreak, what does the WHO need to do to \\ re-establish its reputation and pre-eminence in world health?
}

I

t has been almost 2 years since the world first became aware of the dreadful Ebola epidemic in West Africa that has caused over 11000 deaths in more than 28000 victims. ${ }^{1}$ Weekly surveillance reports from the World Health Organization have led to guarded optimism that the outbreak is almost over. The much discussed, dissected and anticipated pandemic of Ebola filovirus disease never eventuated, and is unlikely to do so. Such a ferocious outbreak with pandemic potential should have been a show piece of the WHO's skills in managing public health emergencies; instead it highlighted deficiencies within the organisation. Criticism of the WHO, both by external voices and from within, has loomed large in the background throughout the outbreak, bringing into question both its purpose and pre-eminence in guiding global health.

\section{"the WHO should incorporate punitive elements into its constitution for member states that fail to comply with its instructions"}

A major criticism of the $\mathrm{WHO}$ has been its failure to declare a public health emergency of international concern (PHEIC) when the outbreak was in its infancy. ${ }^{2}$ It is believed that such a declaration at that time could have resulted in far fewer casualties. It is known that the acute Ebola episode is not the only illness that could have been prevented by effective and timely interventions. There is also a well-documented post-Ebola syndrome in people fortunate enough to recover from the acute illness. In its chronic form, it can lead to a number of ongoing problems such as arthralgia, myalgia, fatigue, hearing loss, anorexia, mood and memory issues. ${ }^{3}$ While these may seem minor compared with the fulminant acute illness, such problems may be enough to render West African labourers unable to work and provide for their families - there may be long-term economic consequences in already impoverished regions. The hospitalisation of a British nurse in the United Kingdom with acute meningitis many months after the original illness has raised awareness that post-Ebola syndrome may have to incorporate acute manifestations. ${ }^{4}$

Australian National University, Canberra, ACT.

sanjaya.senanayake@ act.gov.au

doi: 10.5694/mjal5.01188

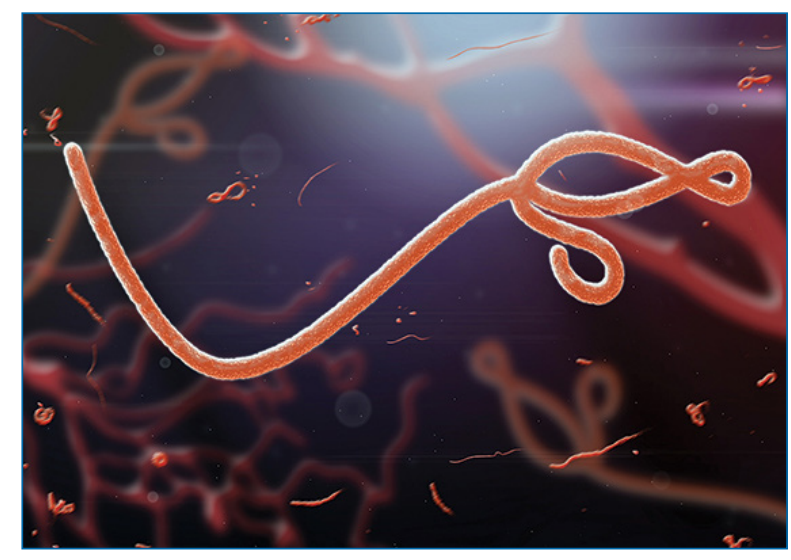

Health Assembly in May 2015, the WHO announced three steps to ameliorate their response to global health security: developing a new global health emergency workforce; combining the secretariat's outbreak and emergency response programs; and creating a US\$100 million emergency contingency fund that is accessible under the Director-General's discretion that is not linked to the announcement of a PHEIC. ${ }^{2}$

However, there are concerns regarding these proposals: finding the resources to fund them; the fact that a $\$ 100$ million may be insufficient to cover the aid and economic losses brought about by a large outbreak; and that the fundamental problems related to the structure of the WHO have not been addressed. ${ }^{2}$ This final point is part of a larger debate about how to make the WHO relevant in 2016. After all, it is not easy being the leader in global health security - the criticism of the WHO's inadequate response to Ebola comes not long after the organisation underwent examination for its handling of the 2009 H1N1 influenza pandemic. ${ }^{6}$ It can be difficult for any large organisation to adapt to change and, since it was founded in 1948, the WHO has had to confront a rapidly changing world. Within decades, the political and economic global landscape has become unrecognisable with the Cold War ending, and developing nations such as India and China becoming economic giants. The emergence of new international health institutions such as Médecins Sans Frontières; the Global Fund to Fight AIDS, Tuberculosis and Malaria; the Bill and Melinda Gates Foundation; and the GAVI Alliance also cannot be ignored. ${ }^{7}$ These non-governmental organisations operate, proselytise and criticise in a manner often not possible for the $\mathrm{WHO}$, whose member states are usually the very stakeholders at the centre of such humanitarian operations. The WHO must tread carefully. However, rather than viewing these 
organisations as challengers to the WHO's pre-eminence, they should be considered as skilled and resourced allies that the WHO can partner with and delegate to.

A number of structural issues have been identified within the WHO: the skill mix of mainly medical and administrative personnel leaving deficiencies in other areas; the need to provide an internal separation between its technical and political and governance sections; and the restructuring of its regional offices. ${ }^{7}$ This last point is salient because during the Ebola outbreak, there was apparently tension between the WHO's Geneva headquarters and its regional and country offices in Africa over issues such as blocking visas for foreign aid workers and the delay of offloading medical supplies. ${ }^{2}$ With regard to finances, the WHO surprisingly relies on voluntary funding for over $70 \%$ of its budget - and presumably is subject to the lobbying pressures that accompany such funding. The reversal of this trend through greater contributions by member states may not obviate lobbying pressures, but it would be preferable to the financial uncertainty of the current arrangement and would provide an affirmation by member states of their support for the WHO.

Such changes could transform the WHO into a highly efficient organisation with easily mobilised financial and human elements that can achieve its core functions. However, there is a further issue. During the Ebola outbreak, the Director-General was apparently put under political pressure not to declare a PHEIC. Trade and quarantine enforcement and travel bans were instituted, despite the Director-General's recommendations not to do so. Only 64 of 196 states have developed core health system capacities, even though it is mandated under the International Health Regulations. ${ }^{2}$ Thus, the WHO should incorporate punitive elements into its constitution for member states that fail to comply with its instructions, especially in the setting of an acute epidemic, where time is of the essence and protracted debate is impractical. UN sanctions backed by member states are evidence that such a more punitive approach is not novel; and the WHO is part of the UN. Therefore, sanction is one possible strategy that the WHO could use on such occasions - it is important for the $\mathrm{WHO}$ not to remain a toothless tiger.

The WHO has been accused and judged on the world stage for its inadequacies during the West African Ebola outbreak. Now it must be forgiven, not just as a gesture of compassion, but also because of the necessity of its existence. The world is more connected than ever before. The ease of global travel, real-time communication through the media and social media, as well as free-trade agreements between a variety of nations has created an environment where a single overarching organisation can represent the interests of our global community. With the right structure, powers and learning how to engage other new global health institutions in its core functions, we can be optimistic about the WHO's role in maintaining global health security.

Competing interests: No relevant disclosures.

Provenance: Commissioned; externally peer-reviewed. $\mathbf{c}$

(c) 2016 AMPCo Pty Ltd. Produced with Elsevier B.V. All rights reserved.

References are available online at www.mja.com.au. 
1 World Health Organization. Ebola situation reports. Geneva: WHO, 2015. http://apps.who.int/ebola/ebola-situationreports (accessed Oct 2015).

2 Gostin LO. The future of the World Health Organization: lessons learned from Ebola. Milbank Q 2015; 93: 475-479.

3 Carod-Artal FJ. Post-Ebolavirus disease syndrome: what do we know? Expert Rev Anti Infect Ther 2015; 13: 1185-1187.

4 Ebola caused meningitis in nurse Pauline Cafferkey. BBC News 2015; 21 Oct. http://www.bbc.com/news/uk-scotlandglasgow-west-34592132 (accessed Oct 2015).

5 World Health Organization. Report of the Ebola Interim Assessment Panel. Geneva: WHO, 2015. http://www.who. int/csr/resources/publications/ebola/report-by-panel.pdf (accessed Oct 2015).

6 World Health Organization. The international response to the influenza pandemic: WHO responds to the critics. Geneva: WHO, 2010. http://www.who.int/csr/disease/swineflu/notes/ briefing_20100610/en (accessed Oct 2015).

7 Clift C. What's the World Health Organization for? Final report from the Centre on Global Health Security Working Group on Health Governance. London: Royal Institute of International Affairs, 2014. https://www.chathamhouse.org/sites/files/ chathamhouse/field/field_document/20140521WHOHealthG overnanceClift.pdf (accessed Oct 2015). 